\title{
Diversidade genética de Cucurbita pepo, $C$. argyrosperma e C. ficifolia empregando marcadores microssatélites
}

\author{
Daniela Priori ${ }^{1}$; Rosa Lía Barbieri²; Caroline M Castro² ${ }^{2}$ Antonio C de Oliveira ${ }^{1}$; Juliana CB Vilela ${ }^{2}$; \\ Claudete C Mistura ${ }^{1}$

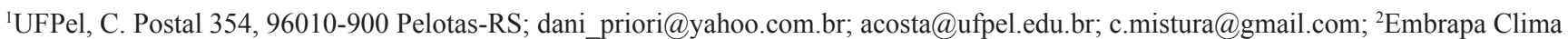 \\ Temperado, C. Postal 403 96010-971 Pelotas-RS; lia.barbieri@cpact.embrapa.br, caroline.castro@cpact.embrapa.br, jcbrancov@gmail. \\ com
}

\section{RESUMO}

No Sul do Brasil são cultivadas variedades locais das cinco espécies domesticadas de Cucurbita. Dentre elas, as menos estudadas são C. argyrosperma e C. ficifolia. Análises de microssatélites são importantes para a caracterização molecular dessas duas espécies, mas existe a necessidade de primers específicos, ainda não disponíveis. O objetivo desse trabalho foi avaliar a transferibilidade de primers e otimizar a amplificação de locos SSR de C. pepo em C. argyrosperma e $C$. ficifolia, bem como averiguar a diversidade genética entre diferentes acessos de germoplasma destas espécies. Foram utilizados dez acessos de $C$. pepo, nove de $C$. argyrosperma e cinco de $C$. ficifolia do Banco Ativo de Germoplasma de Cucurbitáceas da Embrapa Clima Temperado. O DNA foi extraído em bulk das folhas de cinco indivíduos de cada acesso. Foram usados 40 primers SSR desenvolvidos para C. pepo. Em C. pepo, 35 primers $(87,5 \%)$ amplificaram, em C. argyrosperma, 34 primers (85\%) e em $C$. ficifolia, 32 primers $(80 \%)$. Portanto a taxa de transferibilidade de locos SSR de C. pepo para C. argyrosperma e C. ficifolia foi alta, indicando que podem ser empregados na caracterização molecular destas espécies.

Palavras chave: Cucurbitaceae, abóboras, caracterização molecular, recursos genéticos, variedades locais.

\begin{abstract}
Genetic diversity of Cucurbita pepo, C. argyrosperma and C. ficifolia accessions evaluated through microsatellite markers

Landraces of five domesticated species of Cucurbita are cultivated in southern Brazil. Among them C. argyrosperma and $C$. ficifolia are the least studied. Microsatellite markers are important for the molecular characterization of these two species, but there is a need for specific primers, not yet available. The aim of this study was to evaluate the transferability of primers and optimize the amplification of SSR loci in C. pepo, C. argyrosperma and C. ficifolia and also evaluate genetic diversity in different accessions of germplasm in these species. We used ten accessions of $C$. pepo, nine of $C$. argyrosperma and five of $C$. ficifolia from the Genebank of Cucurbitaceae from Embrapa Temperate Agriculture. DNA was extracted in bulk from the leaves of five individuals of each accession. 40 SSR primers developed for $C$. pepo were used. In $C$. pepo 35 primers $(87.5 \%)$ amplified, in C. argyrosperma, 34 primers (85\%), and in C. ficifolia, 32 primers $(80 \%)$. The transferability of SSR loci in C. pepo to C. argyrosperma and C. ficifolia was 85 and $80 \%$ respectively. The transferability of SSR loci from $C$. pepo to $C$. argyrosperma and C. ficifolia was 85 and $80 \%$ respectively. Thus, the transferability rate of SSR loci developed for $C$. pepo to C. argyrosperma and C. ficifolia was high, indicating that they can be used in molecular characterization of these species.
\end{abstract}

Keywords: Cucurbitaceae, squashes, molecular characterization, genetic resources, landraces.

(Recebido para publicação em 28 de julho de 2012; aceito em 14 de junho de 2013) (Received on July 28, 2012; accepted on June 14, 2013)

$\mathrm{N}_{\mathrm{e}}^{\circ}$ país, o cultivo das abóboras bastante difundido e tem importância por fazer parte da alimentação das populações de várias regiões (Ramos \& Queiroz, 2005). As abóboras pertencem ao gênero Cucurbita $(2 \mathrm{n}=2 \mathrm{x}=40)$, da família Cucurbitaceae. O gênero Cucurbita é formado por 24 espécies, sendo que cinco dessas espécies são domesticadas: C. argyrosperma, C. ficifolia, $C$. maxima, C. moschata e C. pepo (Lira-Saade, 1995, citado por Ferreira, 2008).
No Brasil são cultivadas variedades locais das cinco espécies domesticadas de Cucurbita (Priori et al., 2010). Destas, as duas espécies mais cultivadas no território nacional são $C$. maxima e $C$. moschata.

Cucurbita ficifolia, conhecida popularmente como gila, é esporadicamente cultivada em quintais no Sul do Brasil. Os frutos são ocasionalmente comercializados em feiras de agricultura familiar e em mercados de hortifrutigranjeiros. O cultivo de variedades locais ocorre em localidades isoladas no extremo sul do Brasil e em municípios da serra gaúcha, localizados na antiga rota dos tropeiros (Heiden et al., 2007). C. ficifolia apresenta menor variabilidade genética quando comparada às demais espécies cultivadas do gênero, com poucas variações nos padrões de coloração e dimensões dos frutos e sementes. Os frutos são utilizados no preparo de um doce tradicional de herança portuguesa, denominado "doce de gila".

Cucurbita argyrosperma compreende variedades locais conhecidas popularmente como mogango-de-pescoço, 
mogango gringo ou abóbora-batata-doce. Os frutos de C. argyrosperma apresentam variações no tamanho e na curvatura do pescoço. A coloração externa do fruto é branca ou amarelada, com listras verde-escuras. A casca é dura, à semelhança dos mogangos tradicionais (C. реро). Os frutos são utilizados na alimentação humana e animal (Heiden et al., 2007).

Cucurbita pepo é a espécie que apresenta a maior variabilidade genética entre as espécies do gênero (Paris, 2001). Esta variação é responsável por uma multiplicidade de usos e por nomes populares (como mogango, abóbora-estrela, abóbora-de-coco, poronguinho, abóbora-ovo, abóbora-italiana e zuchetti). Os frutos são usados na alimentação humana e animal, e também na ornamentação de ambientes (Heiden et al., 2007). As variedades locais dessas espécies de Cucurbita representam um patrimônio genético e cultural da agricultura familiar no Brasil. Estes recursos genéticos, devidamente caracterizados, constituem fontes de genes para os programas de melhoramento. A caracterização é uma atividade prioritária na estratégia de abordagens e manejo de coleções e bancos de germoplasma, pois consiste em obter dados para descrever, identificar e diferenciar os acessos (Valls, 2001).

Para a caracterização molecular, os marcadores do tipo microssatélites têm elevada utilização por apresentarem abundância e uniformidade na sua distribuição no genoma, natureza multialélica e codominante, fácil detecção por reação de polimerização em cadeia, necessidade de baixa quantidade de DNA, alta reprodutibilidade e baixo custo (Sharma et al., 1995; Santos et al., 2007). Porém, para a amplificação de locos de microssatélites, o conhecimento de sua seqüência de DNA é necessária, o que implica que o desenvolvimento de primers específicos para esse tipo de análise seja um processo caro e demorado (Zucchi et al., 2003). No entanto, existe a possibilidade de transferir primers microssatélites entre espécies aparentadas, o que reduz consideravelmente os custos e o tempo das investigações genéticas (Lorieux et al., 2000).
Por exemplo, sucesso na transferência de SSR (Simple Sequence Repeats) entre espécies dentro de um mesmo gênero tem sido relatado em Olea (Rallo et al., 2003), Limonium (Palop et al., 2000), Prunus (Wuensch \& Hormaza, 2002), Pinus (González-Martínez et al., 2004), Triticum (Adonina et al., 2005) e Cucumis (Ritschel et al., 2004). Outro caso de sucesso na transferibilidade de primers microssatélites de Euterpe edulis para E. oleracea foi relatado por Oliveira et al. (2010), onde os sete loci testados apresentaram 100\% de aproveitamento.

A Embrapa Clima Temperado mantém o Banco Ativo de Germoplasma de Cucurbitáceas do Sul do Brasil. São conservados 539 acessos de diferentes espécies domesticadas: Cucurbita argyrosperma, C. ficifolia, C. maxima, C. moschata, C. pepo, Cucumis melo, Cucumis sativus, Citrullus lanatus, Sicana odorifera, Momordica charantia, Lagenaria siceraria e Luffa cylindrica. A quase totalidade destes acessos se caracteriza por ser variedades locais cultivadas na Região Sul do Brasil, por agricultores familiares. A caracterização de germoplasma tem grande importância porque estabelece uma identidade para cada acesso do banco, permitindo conhecer dados que possibilitam estudar a diversidade genética existente entre os acessos conservados, molecular, físicoquímica.

Como não existem primers de microssatélites desenvolvidos para $C$. argyrosperma e para $C$. ficifolia, os primers de microssatélites desenhados para $C$. pepo podem ser usados como uma alternativa para encontrar regiões semelhantes no genoma, uma vez que pertencem ao mesmo gênero. Neste sentido, o objetivo do trabalho foi avaliar a transferibilidade de primers e otimizar a amplificação de locus SSR de C. pepo em $C$. argyrosperma e $C$. ficifolia bem como averiguar a diversidade genética entre diferentes acessos destas três espécies.

\section{MATERIAL E MÉTODOS}

Foi realizada uma busca no National Center for Biotechnology Information (NCBI) para selecionar primers microsatélites já desenvolvidos para Cucurbita. Foram selecionados 40 pares de primers SSR (Tabela 1) desenhados para C. pepo, desenvolvidos pelo Applied Life Sciences the Institut of Biotechnology in Plant Production, Department for Agrobiotechnology of the BOKU-University of Natural Resources, na Austria. Os primers foram selecionados a partir de informações disponíveis como número de alelos e regiões conservadas.

Vinte e quatro acessos de germoplasma coletados na agricultura tradicional do Rio Grande do Sul foram utilizados, sendo nove de $C$. argyrosperma, cinco de $C$. ficifolia e dez de C. pepo (Tabela 2). Os acessos fazem parte do acervo do Banco Ativo de Germoplasma de Cucurbitáceas da Embrapa Clima Temperado. O trabalho foi desenvolvido em 2009 e 2010 no Laboratório de Biologia Molecular da Embrapa Clima Temperado, em Pelotas-RS.

As plantas foram cultivadas em sacos plásticos de poliestireno preto preenchidos com substrato, em casa de vegetação. O DNA foi extraído em bulk das folhas jovens de cinco indivíduos de cada acesso. A extração foi realizada de acordo com o protocolo descrito por Ferreira \& Grattapaglia (1998). Os testes de qualidade e a quantificação do DNA foram feitos em gel de agarose $0,8 \%$, contendo $0,2 \mu \mathrm{g} / \mathrm{mL}$ de brometo de etídio. Foram aplicados $2 \mu \mathrm{L}$ de cada amostra de DNA, com $3 \mu \mathrm{L}$ de corante tipo TC (azul de bromofenol 0,25\% e sacarose $40 \%$ ). O DNA foi quantificado no gel por comparação com os padrões de bandas do marcador $\lambda$ DNA Hind III. Após a quantificação, o DNA foi diluído em TE para uma concentração de $25 \mathrm{ng} / \mu \mathrm{L}$.

As reações de amplificação de microssatélites (PCR-SSR) foram realizadas em volume final de reação $25 \mu \mathrm{L}$ contendo, 10,2 $\mu \mathrm{L}$ de $\mathrm{H}_{2} \mathrm{O}, 1,4 \mu \mathrm{Lde} 10 \mathrm{x}$ PCR Buffer, 1,6 $\mu \mathrm{L}$ de $\mathrm{MgCl}(50 \mathrm{mM})$, $1,05 \mu \mathrm{L}$ de DNTPs $(12,5 \mathrm{mM}), 1,08 \mu \mathrm{L}$ de BSA $(10 \mathrm{mg} / \mu \mathrm{L}), 0,7 \mu \mathrm{L}$ de cada primer (Forward e Reverse) $10 \mu \mathrm{M}, 0,04$ $\mu \mathrm{L}$ de Taq DNA Polimerase $(5 \mathrm{u} / \mu \mathrm{L}) \mathrm{e}$ $2,0 \mu \mathrm{L}$ de DNA( $5 \mathrm{ng} / \mu \mathrm{L})$. As amplificações foram realizadas em termociclador Applied Bio Systems Gene Amp PCR 
System 9700, programado para uma etapa inicial de desnaturação do DNA a $94^{\circ} \mathrm{C}$ por 4 min e $40 \mathrm{seg}$, seguido de 30 ciclos de 0,15 min a $94^{\circ} \mathrm{C}$ (desnaturação), $0,10 \mathrm{~min}$ a $60^{\circ} \mathrm{C}$ (anelamento) e $0,15 \mathrm{~min}$ a $72^{\circ} \mathrm{C}$. Por fim, uma etapa de 5 min a $72^{\circ} \mathrm{C}$. As temperaturas de anelamento variaram de 50 a $60^{\circ} \mathrm{C}$, conforme a temperatura do primer utilizado. Os fragmentos amplificados foram separados por eletroforese horizontal em gel de agarose $3 \%$, corado com brometo de etídio $(0,2 \mu \mathrm{g} / \mathrm{mL})$ e tampão TBE1X (Tris-Borato $90 \mathrm{mM}$, EDTA $2 \mathrm{mM}$ ). Os géis foram visualizados em transiluminador de luz ultravioleta (UV). As imagens foram capturadas em câmara digital e armazenadas em computador para avaliação dos padrões de bandas. O marcador $1 \mathrm{~Kb}$ Plus DNA ladder foi utilizado como referência de peso molecular para estimar os tamanhos dos produtos da amplificação. O tamanho das bandas foi estimado por meio do programa computacional Bio - 1D Advanced - Vilber Lourmat SAS, 2006 (software de análise).

Os marcadores obtidos foram analisados com o software NTSYS-PC (Rohlf, 2000). Os alelos amplificados foram identificados de acordo com o peso molecular das bandas geradas e convertidos em uma matriz de dados binários, a partir da qual foi estimado: i) o conteúdo de informação de polimorfismo (PIC) de cada marcador:

$\mathrm{PIC}=1-\sum p_{i^{2}} 1-\sum p_{i}{ }^{2}$ onde, pi é a frequência ao quadrado do alelo i; ii) a similaridade genética entre os acesso com o emprego do coeficiente de similaridade de Dice (Dice, 1945) pelo software NTSYS-PC 2.1, conforme a equação:

$$
S_{D}=\frac{2 V_{i j}}{2 V_{i j}+W_{i j}+x_{i j}}
$$

onde $\mathrm{v}_{i j}$ refere-se às bandas em comum em $i$ e $j, \mathrm{w}_{i j}$ é o número de bandas presentes em $i$ e ausentes em $j, x_{i j}$ é o número de bandas presentes em $j$ e ausentes em $i$.

Com base na matriz de similaridade genética foi construído um dendrograma, por meio do método de agrupamento da distância média UPGMA (Unweighted Pair Group Method with Arithmetic Average). O ajuste entre a matriz de similaridade e o dendrograma foi estimado pelo coeficiente de correlação cofenética (r), conforme Sokal \& Rohlf (1962), por meio do programa computacional NTSYSpc 2.1. Esse coeficiente traduz a relação momento produto, calculado entre os elementos da matriz original e os da matriz cofenética, resultante da simplificação proporcionada pelo método de agrupamento, depois da construção do dendograma. Valores de $(r)$ acima de 0,8 indicam boa representatividade entre as distâncias (Bussad et al., 1990). A estabilidade dos agrupamentos foi computada por meio da análise de Bootstraping com 1000 replicações, com a utilização do programa computacional Winboot (Yap \& Nelson, 1996).

\section{RESULTADOS E DISCUSSÃO}

Foi possível observar polimorfismo a partir da análise de marcadores microssatélites nas três espécies de Cucurbita avaliadas, utilizando primers desenhados para $C$. pepo. O produto das amplificações foi satisfatório, permitindo verificar que diferentes níveis de transferibilidade foram obtidos (Figura 1). A análise de 24 acessos de Cucurbita por meio de 35 iniciadores gerou um total de 105 marcadores SSR, com variação de um a quatro alelos por loco, dos quais $56(53,33 \%)$ foram polimórficos, evidenciando que há variabilidade genética entre os acessos analisados. Demonstra, também, a eficiência dos marcadores microssatélites na quantificação da variabilidade genética presente. Das três espécies analisadas, C. pepo apresentou a maior variabilidade.

As frequências alélicas variaram de 1 a 0,04 entre as três espécies, sendo que a média geral dessas frequências foi de 0,35. Segundo Schuster et al. (2006), se as frequências alélicas são conhecidas, é possível estimar as probabilidades de identidade de um determinado acesso com qualquer outro, com base na análise de DNA. O peso molecular dos fragmentos de amplificação gerados variou de 85 pb a 303 pb, dos quais $70 \%$ apresentaram peso médio inferior a 200 pb. O padrão de bandas e a qualidade dos produtos da amplificação são mostrados na Figura 1.

O conteúdo de informação de polimorfismo (PIC) variou de 0,09 a 0,89 , com média de 0,42 , sendo que os iniciadores que evidenciaram maiores informações de polimorfismo foram CMTP204, СMTP46, СMTP193, CMTP187, CMTP62, СMTP68, com respectivamente $0,89,0,86,0,84$, $0,83,0,80$ e 0,74 . O PIC fornece uma estimativa do poder discriminatório de um marcador (Weir, 1996). Pode-se inferir que os marcadores utilizados foram eficientes na discriminação dos acessos. Essas observações estão de acordo com resultados obtidos por Inan et al. (2012), os quais relataram um alto grau de polimorfismo avaliando 16 acessos de C. pepo, 4 de C. moschata e 4 de $C$. maxima com 8 locos ISSR (Inter Simple Sequence Repeat) e 8 locos SRAP (Sequence Related Amplified Polymorphism). Foram obtidas 60 bandas polimórficas por meio dos locos ISSR e 71 bandas com os locos SRAP, apresentando valores altos de PIC que variaram de 0,60 a 0,90 com média de 0,73 .

Dentre os 40 primers testados para C. argyrosperma, verificou-se que 34 (85\%) amplificaram, mostrando um total de 49 alelos com frequências alélicas variando entre 11 e $100 \%$ no conjunto de nove acessos analisados. Destes, 20 primers foram monomórficos e 14 detectaram polimorfismo. Para C. ficifolia, $32(80 \%)$ primers amplificaram, sendo que 20 foram monomórficos e 12 foram polimórficos, gerando um total de 47 alelos, com frequências alélicas variando de 0,2 a 1. Em C. argyrosperma e $C$. ficifolia o padrão de amplificação foi de baixa qualidade e as bandas não ficaram nítidas para três primers, CMTP190, CMTP138 e CMTP193.

A transferibilidade de locos SSR de $C$. pepo para $C$. argyrosperma e $C$. ficifolia encontrada no presente trabalho, de 85 e $80 \%$ respectivamente, foi menor do que aquela relatada por Yamamoto et al. (2001) para a transferência de primers SSR desenhados para maçã (Malus domestica) e amplificados em pêra (Pyrus communis), com 100\% de sucesso). No entanto, foi superior ao relatado para a transferibilidade de primers SSR entre diferentes espécies 
Tabela 1. Primers desenhados para Cucurbita pepo e selecionados para a transferibilidade em Cucurbita argyrosperma e C. ficifolia (primers designed for Cucurbita pepo and selected to the transferability in Cucurbita argyrosperma and C. ficifolia). Pelotas, Embrapa Clima Temperado, 2011.

\begin{tabular}{|c|c|c|c|c|}
\hline Nome & Forward & Reverse & pb & temp. \\
\hline СМТР46 & TTCCCTTCTGCAGAGATGCT & CCATGCGCATAATTGTATCG & 142 & 60 \\
\hline СМТР33 & AATGCGTTTGAACAAAGCTG & GGCTGTTAAAATTTCCTCGAT & 171 & 58 \\
\hline СМТР48 & TTTGCAGTACGCTGCAGAAC & GGATCCTTCTCGTGGTGGTA & 228 & 60 \\
\hline СМТР61 & TTTGCAGTACGCTGCAGAAC & GGATCCTTCTCGTGGTGGTA & 118 & 60 \\
\hline СМТР86 & GCTCTTGGACAAGAATGGTCA & ATGGCTTCTGGTGGTTTGTC & 133 & 60 \\
\hline CMTP131 & GCACTTGAATCTTCGTCAAC & CGAGAAAGAATTAACGAGCA & 117 & 55 \\
\hline CMTP132 & CCATTTCCATTTCCATTTCA & AGGTTAGAAACAGGGGGAAC & 151 & 58 \\
\hline CMTP158 & CCGTAGAGATGTCAGAGACAAGG & AGGGATGCTCATCACACCTC & 134 & 60 \\
\hline СMTP174 & GCCGGAACCAGACTTCTC & СССТСССТТСССАТТАААС & 176 & 58 \\
\hline СМТР141 & ATTCATGTCATACTACCGACTTC & CGGATTTATAAGATGGCAAG & 135 & 55 \\
\hline СМТР190 & CGGGGAAGAGAGGTTTAGGT & CCСATACATTCCCATATAACACC & 210 & 59 \\
\hline СМТР182 & CACGAAGATTTGATGGCCTTA & GGATTGGGATGGTGAAGATG & 138 & 60 \\
\hline СМТР204 & AGAAGGAGGAGAGCGGAAAG & ATAAGATCCCAACCCCAACC & 357 & 60 \\
\hline СMTP210 & GTGGAAGTTACTGCGATTGG & GCAAAGAATGTCCTCAGCAG & 117 & 58 \\
\hline СМТР193 & GGTGACGGCAAGAAAAGCTA & GCTGACCCTCTCTCCСТCTC & 186 & 60 \\
\hline СМТР201 & AGGAGTGGTGGGCTAATACG & TGAAATTGAGGGAGGGAGAG & 110 & 59 \\
\hline СМТР247 & GGGTGTGTTGAGGATTGGTT & ATCACATTTTCTCCССАССА & 123 & 60 \\
\hline CMTP17 & ACTGCTCAATAAGGCAAGGA & AAACAAGAGTGCACAAACAGG & 84 & 58 \\
\hline СMTP107 & CGATGATGAACAGGAAGACG & TCACATCCATTCCССТCTCT & 109 & 59 \\
\hline СМТР62 & GTGCCCGTCAGTCGGAAT & TGTCGACGAAGATAGCAATAGCA & 100 & 60 \\
\hline СМТР58 & TCGGAGAAACTCGACACTCC & TCCCAGCACCATCAGGATAC & 102 & 60 \\
\hline СМТР66 & ACGACATGAGGGAAGATTCG & TTCAATGCCATTCGCCTAC & 128 & 60 \\
\hline СМТР84 & GCGGTAACAGGTTGTTTGGT & CCATCAGGATACCCTACAAAGG & 150 & 60 \\
\hline СМТР97 & CCACACACCAATCGTTGAAG & CGCAGAATCTCGAAACACAA & 166 & 60 \\
\hline СМТР126 & ACCTCAAACCCСТTTTGTG & GGAAGAAGAAGGAGGAGGAG & 117 & 57 \\
\hline СМТР120 & AACCGGAACACCTTTATGACC & TTCAAGAAGGTTCCGAAGGA & 164 & 60 \\
\hline СМТР130 & GCCCATTTCTGGAGAGATAGTA & GAGGAGAGATGCAGAGCAAC & 169 & 57 \\
\hline CMTP144 & ATGGCTTCCAAGCTCCTCTT & GTCGGCCATGAGCTTGAG & 105 & 60 \\
\hline CMTP133 & TGCTCTCTTTGAATTCAGCAT & AGGGATCTTCCATTTCCAAT & 113 & 57 \\
\hline СМТР187 & АACAАTCCTCGCCTCAАATC & ATGAAAATGGGAAGCCAGAG & 189 & 60 \\
\hline СМТР219 & TTCATCATCGTCAGCAAAGC & GCACATGCAGCACTCTGACT & 117 & 60 \\
\hline СМТР207 & GACGAACGAAGCATGTTGAG & GGTCAGCAAGGTCAGAAAGG & 156 & 60 \\
\hline СМТР224 & CACCGACGACTCCATCATC & CTTCTTGTCCCCAAAATCACA & 151 & 60 \\
\hline СМТР261 & AAATGCCAGCCCAAATCAT & GATGGCTGCCACTTCCTCTA & 187 & 60 \\
\hline СМТР68 & CACACCCATTTCATTTTGACC & ATTGATTGGGACGTGAGGAA & 180 & 60 \\
\hline CMTP125 & CTTGTTCCGCAGCATCAG & AGTGAGAGGGAGACGCAAAG & 115 & 59 \\
\hline СМТР138 & AAAGGTTTCCACATCCTTG & GAAAAGGAAAAAGTGTTCAAAG & 103 & 55 \\
\hline СМТР209 & TCACTTTACAACCAGAAGCTGA & CACTTTGCTGCTCATCCAC & 116 & 57 \\
\hline СМТР83 & TGACCATTTTGCAGATTGAGA & CTTCCGGAGACGAAAGAGTC & 112 & 59 \\
\hline СМТР127 & TTCCTCTGTTTCCGTCAATG & CACAAAAGGGGTTTGAGGTT & 112 & 58 \\
\hline
\end{tabular}

$\mathrm{pb}=$ pares de base (base pairs), temp. = temperatura de anelamento (annealing temperature).

da família Poaceae, como de arroz (Oryza sativa) para espécies de bambu (Bambusa spp.), que foi de 68,3\% (Chen et al., 2010) e de milho (Zea mays) para espécies de Miscanthus, que foi de 74,5\% (Hernandez et al., 2001). Os resultados obtidos foram superiores também aos estudos realizados com outras espécies de cucurbitáceas, onde um conjunto de primers de melão (Cucumis melo), otimizados e testados em abóbora (Cucurbita moschata) e bucha (Luffa cilindrica), teve 31,25\% de transferibilidade (Leite et al.,
2007); e de melão (Cucumis melo) para pepino (Cucumis sativus), com aproximadamente $50 \%$ de sucesso (Danin-Poleg et al., 2001).

Os resultados encontrados neste estudo apresentaram valores quase iguais aos encontrados por Gong et al. 
Tabela 2. Acessos de variedades locais de Cucurbita argyrosperma, C. ficifolia e C. pepo do Rio Grande do Sul submetidos à caracterização molecular (accessions of Cucurbita argyrosperma, C. ficifolia and C. pepo landraces from Rio Grande do Sul submitted to molecular characterization). Pelotas, Embrapa Clima Temperado, 2011.

\begin{tabular}{|c|c|c|c|c|}
\hline Acesso & Espécie & Nome popular & Município de procedência & Coordenadas geográficas \\
\hline $\mathrm{C} 16$ & C. argyrosperma & abóbora menina & Santana da Boa Vista & $30^{\circ} 52^{\prime} 23.56^{\prime \prime} \mathrm{S}, 53^{\circ} 08^{\prime} 03.72^{\prime \prime} \mathrm{O}$ \\
\hline $\mathrm{C} 103$ & C. argyrosperma & mogango de pescoço & São Lourenço do Sul & $31^{\circ} 21^{\prime} 44.17^{\prime \prime} \mathrm{S}, 51^{\circ} 58^{\prime} 46.36^{\prime \prime} \mathrm{O}$ \\
\hline C106 & C. argyrosperma & mogango de pescoço & Rosário do Sul & $30^{\circ} 14^{\prime} 43.12^{\prime \prime} \mathrm{S}, 54^{\circ} 55^{\prime} 15.76^{\prime \prime} \mathrm{O}$ \\
\hline $\mathrm{C} 258$ & C. argyrosperma & abóbora & Santana da Boa Vista & $30^{\circ} 52^{\prime} 23.56^{\prime \prime} \mathrm{S}, 53^{\circ} 08^{\prime} 03.72^{\prime \prime} \mathrm{O}$ \\
\hline C289 & C. argyrosperma & mogango de pescoço & Cerro Grande do Sul & $30^{\circ} 35^{\prime} 49.24^{\prime \prime} \mathrm{S}, 51^{\circ} 45^{\prime} 07.15^{\prime \prime} \mathrm{O}$ \\
\hline C334 & C. argyrosperma & abóbora de pescoço & Pelotas & $31^{\circ} 46^{\prime} 18.18^{\prime \prime} \mathrm{S}, 52^{\circ} 20^{\prime} 32.63^{\prime \prime} \mathrm{O}$ \\
\hline C379 & C. argyrosperma & moranga gringa & São Francisco de Assis & $29^{\circ} 33^{\prime} 04.59^{\prime \prime} \mathrm{S}, 55^{\circ} 07^{\prime} 40.32^{\prime \prime} \mathrm{O}$ \\
\hline C395 & C. argyrosperma & mogango de pescoço & Bagé & $31^{\circ} 19^{\prime} 44.08^{\prime \prime} \mathrm{S}, 54^{\circ} 06^{\prime} 53.40^{\prime \prime} \mathrm{O}$ \\
\hline C401 & C. argyrosperma & abóbora & Pelotas & $31^{\circ} 46^{\prime} 18.18^{\prime \prime} \mathrm{S}, 52^{\circ} 20^{\prime} 32.63^{\prime \prime} \mathrm{O}$ \\
\hline C151 & C. ficifolia & Abóbora gila & Rio Grande & $32^{\circ} 01^{\prime} 59.39^{\prime \prime} \mathrm{S}, 52^{\circ} 05^{\prime} 53.40^{\prime \prime} \mathrm{O}$ \\
\hline $\mathrm{C} 310$ & C. ficifolia & Abóbora gila & São Lourenço do Sul & $31^{\circ} 21^{\prime} 44.17^{\prime \prime} \mathrm{S}, 51^{\circ} 58^{\prime} 46.36^{\prime \prime} \mathrm{O}$ \\
\hline C312 & C. ficifolia & Abóbora gila & Pelotas & $31^{\circ} 46^{\prime} 18.18^{\prime \prime} \mathrm{S}, 52^{\circ} 20^{\prime} 32.63^{\prime \prime} \mathrm{O}$ \\
\hline C375 & C. ficifolia & Abóbora gila & São Lourenço do Sul & $31^{\circ} 21^{\prime} 44.17^{\prime \prime} \mathrm{S}, 51^{\circ} 58^{\prime} 46.36^{\prime \prime} \mathrm{O}$ \\
\hline C453 & C. ficifolia & Abóbora gila & Pelotas & $31^{\circ} 46^{\prime} 18.18^{\prime \prime} \mathrm{S}, 52^{\circ} 20^{\prime} 32.63^{\prime \prime} \mathrm{O}$ \\
\hline C148 & C. pepo & poronguinho & Pelotas & $31^{\circ} 46^{\prime} 18.18^{\prime \prime} \mathrm{S}, 52^{\circ} 20^{\prime} 32.63^{\prime \prime} \mathrm{O}$ \\
\hline C199 & C. реро & mogango amarelo & Encruzilhada do Sul & $30^{\circ} 32^{\prime} 46.00^{\prime \prime} \mathrm{S}, 52^{\circ} 31^{\prime} 35.03^{\prime \prime} \mathrm{O}$ \\
\hline $\mathrm{C} 222$ & C. реро & Abóbora-estrela & Turuçu & $31^{\circ} 25^{\prime} 19.48^{\prime \prime} \mathrm{S}, 52^{\circ} 10^{\prime} 39.00^{\prime \prime} \mathrm{O}$ \\
\hline $\mathrm{C} 224$ & C. реро & Mogango verrucoso & Turuçu & $31^{\circ} 25^{\prime} 19.48^{\prime \prime} \mathrm{S}, 52^{\circ} 10^{\prime} 39.00^{\prime \prime} \mathrm{O}$ \\
\hline $\mathrm{C} 260$ & C. реро & abóbora-ovo & Pelotas & $31^{\circ} 46^{\prime} 18.18^{\prime \prime} \mathrm{S} 52^{\circ} 20^{\prime} 32.63^{\prime \prime} \mathrm{O}$ \\
\hline $\mathrm{C} 276$ & C. реро & abóbora & Pelotas & $31^{\circ} 46^{\prime} 18.18^{\prime \prime} \mathrm{S}, 52^{\circ} 20^{\prime} 32.63^{\prime \prime} \mathrm{O}$ \\
\hline $\mathrm{C} 290$ & C. реро & abóbora-estrela & Pelotas & $31^{\circ} 46^{\prime} 18.18^{\prime \prime} \mathrm{S}, 52^{\circ} 20^{\prime} 32.63^{\prime \prime} \mathrm{O}$ \\
\hline C299 & C. реро & moganguinho alongado & São Lourenço do Sul & $31^{\circ} 21^{\prime} 44.17^{\prime \prime} \mathrm{S}, 51^{\circ} 58^{\prime} 46.36^{\prime \prime} \mathrm{O}$ \\
\hline C377 & C. реро & abobrinha ornamental & São Lourenço do Sul & $31^{\circ} 21^{\prime} 44.17^{\prime \prime} \mathrm{S}, 51^{\circ} 58^{\prime} 46.36^{\prime \prime} \mathrm{O}$ \\
\hline C381 & C. реро & abóbora-estrela & Pelotas & $31^{\circ} 46^{\prime} 18.18^{\prime \prime} \mathrm{S}, 52^{\circ} 20^{\prime} 32.63^{\prime \prime} \mathrm{O}$ \\
\hline
\end{tabular}

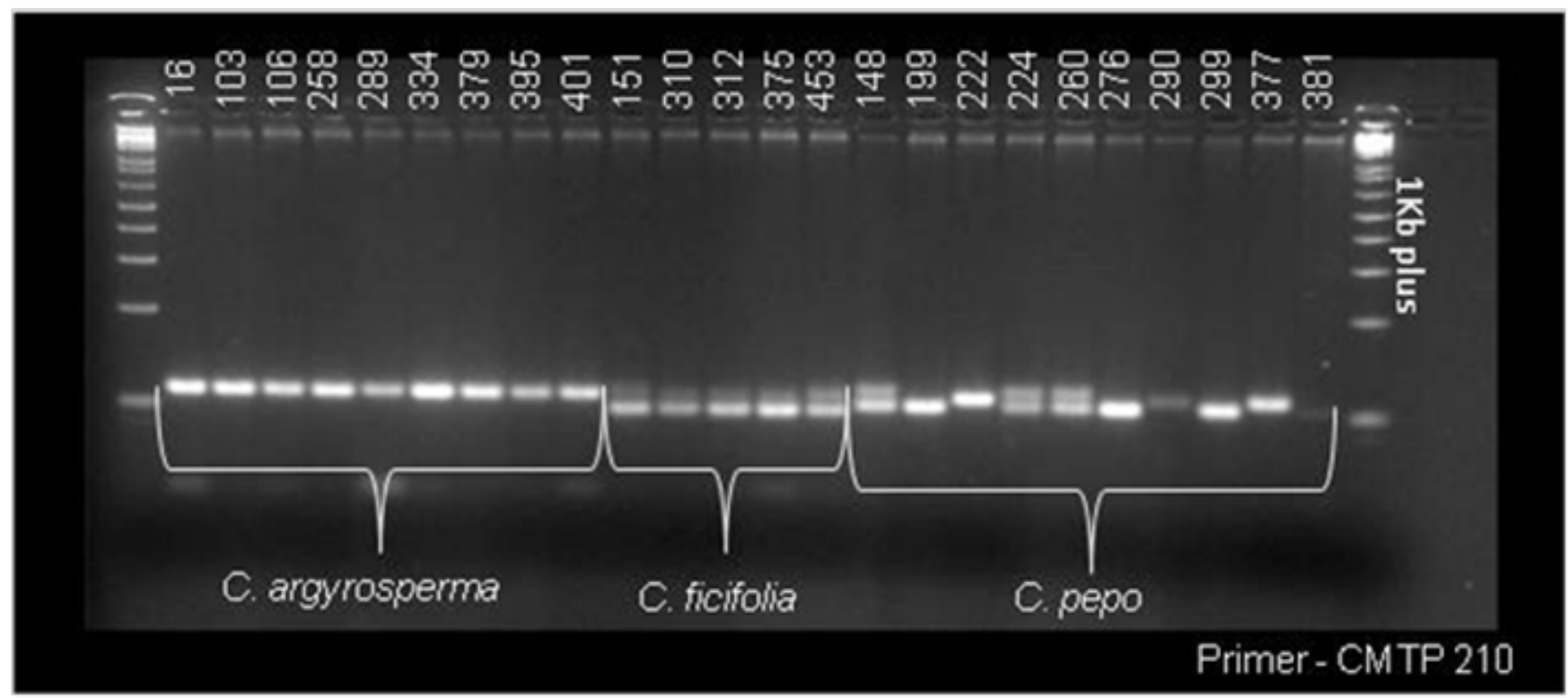

Figura 1. Perfil de amplificação de acessos de Cucurbita argyrosperma, C. ficifolia e C. pepo do Banco Ativo de Germoplasma de Cucurbitáceas da Embrapa Clima Temperado. Os produtos da PCR foram amplificados com o Primer SSR - CMTP210 e revelados em gel de agarose 3,5\%. Marcador: $1 \mathrm{~Kb}$ Plus DNA Ladder (Invitrogen) [profile of amplification for Cucurbita argyrosperma, C. ficifolia and C. pepo accessions from the Genebank of Cucurbitaceae of Embrapa Temperate Agriculture. The PCR products were amplified with the primer SSR - CMTP210 and disclosed in 3.5\% agarose gel. Marker: 1Kb Plus DNA Ladder (Invitrogen)]. Pelotas, Embrapa Clima Temperado, 2011. 


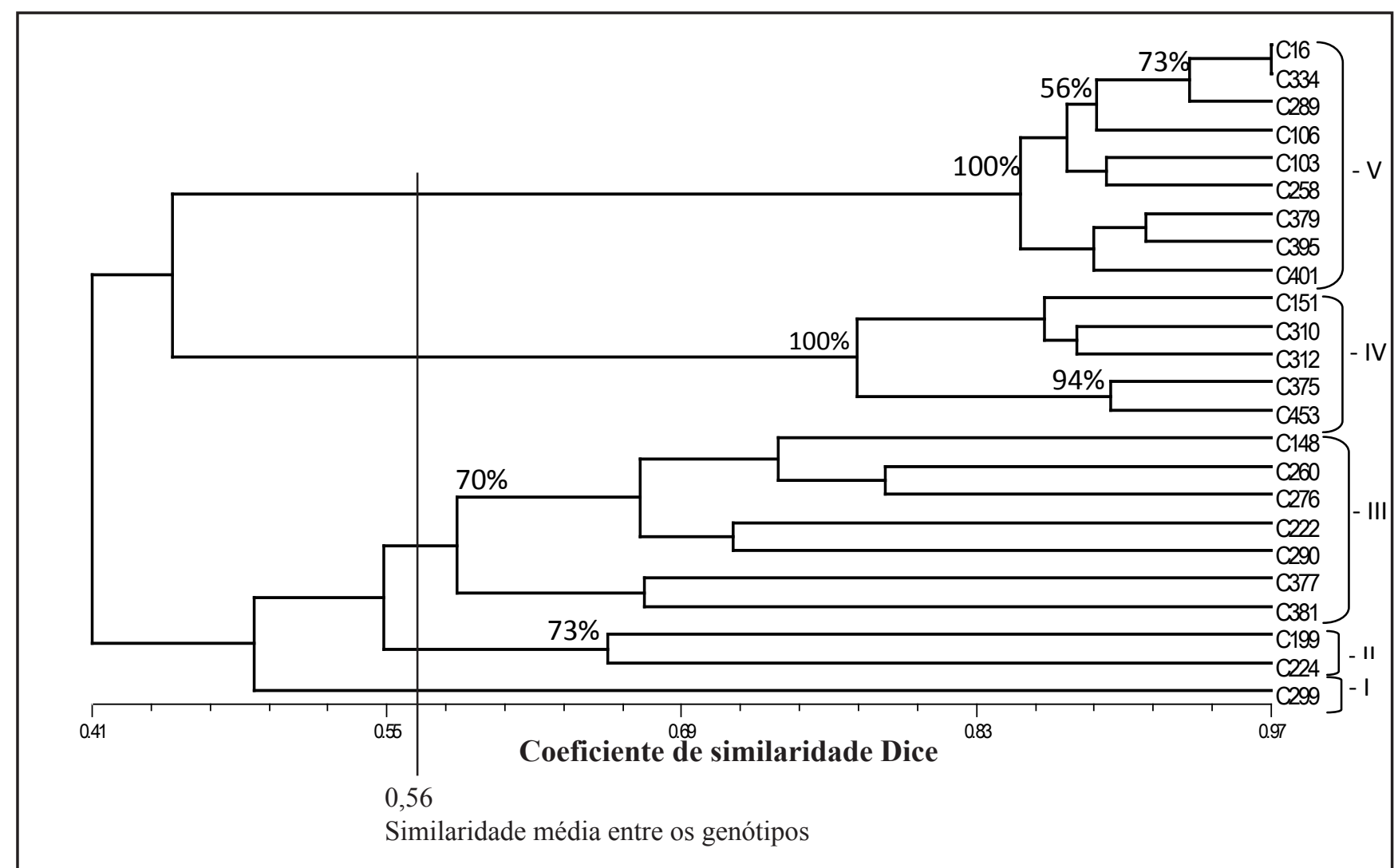

Figura 2. Dendrograma resultante da análise de 24 acessos de Cucurbita argyrosperma, C. ficifolia e C. pepo obtido pelo método de agrupamento UPGMA, com base na matriz de similaridade genética obtida por meio do coeficiente de Dice, utilizando 35 marcadores SSR. Os valores encontrados nos grupos indicam o percentual de vezes que os genótipos agrupam juntos em 1000 ciclos de análise de bootstraping. O valor do coeficiente de correlação cofenética (r) é de 0,92 [dendrogram resulting from analysis of 24 Cucurbita argyrosperma, C. ficifolia and $C$. pepo accessions obtained by the UPGMA method of grouping, on the basis of genetic similarity matrix obtained by Dice coefficient using 35 SSR markers. The values found for groups indicate the percentage of times when genotypes grouped together in 1000 cycles of bootstrapping analysis. The value of cophenetic correlation coefficient (r) is 0.92]. Pelotas, Embrapa Clima Temperado, 2011.

(2008), ao transferir primers SSR de $C$. pepo para C. moschata $(88,1 \%)$. Destes $88,1 \%$ locos que foram transferidos, $30,1 \%$ originaram alelos múltiplos em três genótipos de C. moschata.

Para C. pepo, 35 primers amplificaram, o que equivale a $87,5 \%$ do total de primers avaliados. Destes, 27 primers foram polimórficos, gerando um total de 90 alelos. As freqüências alélicas variaram entre 0,1 e 1 no conjunto de dez acessos analisados. A elevada variabilidade genética detectada nesta espécie já era esperada, pois condiz com dados de caracterização morfológica. De acordo com Paris (2001), C. pepo apresenta a maior variabilidade genética para características morfológicas de fruto no reino vegetal. Esta variação, por conseguinte, é responsável pela maior multiplicidade de usos entre as espécies cultivadas de Cucurbita, que incluem desde a alimentação até o uso ornamental (Heiden et al., 2007).

Na matriz de similaridade genética formada pelos 24 acessos foram obtidos valores altamente variáveis, indo desde quase dissimilares $(0,2), \mathrm{C} 258$ (C. argyrosperma) e C299 (C. pepo), a quase similares $(0,97), \mathrm{C} 16$ e $\mathrm{C} 334$ (C. argyrosperma), com similaridade genética média entre todos os acessos de 0,56. Em C. argyrosperma a similaridade média entre os acessos foi de 0,89 , sendo a similaridade máxima de 0,97 e a mínima de 0,80 , o que evidencia que, nesta espécie, as diferentes variedades locais analisadas são bastante similares entre si. Para as variedades locais de C. ficifolia a similaridade média foi 0,86 sendo a máxima similaridade com valor de 0,89 e a mínima 0,72 . Já em $C$. pepo, a espécie com maior variabilidade genética, foi observada a maior dissimilaridade genética, com valor médio de 0,48 , apresentando similaridade máxima de 0,72 e mínima 0,20 , respectivamente. É importante ressaltar que o valor da similaridade máxima entre dois acessos de C. pepo (C148 e C276) foi igual ao valor da similaridade mínima encontrada entre os acessos mais dissimilares de C. ficifolia (C151 e C453).

A análise da matriz de similaridade genética evidenciou que os acessos mais similares geneticamente foram $\mathrm{C} 16 \mathrm{e}$ C334, com valor de 0,97. Estes acessos são de $C$. argyrosperma coletados nos municípios de Santana da Boa Vista e São Lourenço do Sul, respectivamente. Essa espécie possui baixa variabilidade genética para caracteres morfológicos quando comparada às demais do gênero Cucurbita. Os frutos apresentam variações apenas no tamanho e na curvatura do pescoço (Heiden et al., 2007). Como há poucos relatos na literatura sobre caracterização de $C$. argyrosperma, e nenhum estudo de análise molecular, 
os dados apresentados neste trabalho poderão servir como referência para futuros trabalhos com a espécie.

Considerando a espécie C. ficifolia, os acessos C375 e C453 foram os mais similares entre si, com similaridade genética de 0,89 . Os acessos mais divergentes entre os cinco analisados nesta espécie foram $\mathrm{C} 151$ e C453, com valor de 0,72. Esses dados reforçam a baixa variabilidade relatada quando são considerados caracteres morfológicos em frutos de $C$. ficifolia (Heiden et al., 2007). Para C. pepo, o acesso C222 é o mais divergente dos demais da mesma espécie, apresentando valor de 0,4. Os acessos C276 e C148 foram os mais similares em C. pepo, com similaridade genética de 0,74. Ambos os acessos são variedades locais de abóboras ornamentais cultivadas em Pelotas, com formato de fruto e coloração da casca bastante parecidos.

O dendrograma gerado pode ser visto na Figura 2. Foi evidenciada a formação de cinco grupos distintos, gerados a partir dos marcadores de SSR, com o emprego da similaridade média $(0,56)$ como critério para a separação. As diferentes espécies ficaram em distintos grupos, com os acessos de C. pepo distribuídos nos grupos I, II e III; todos os acessos de C. ficifolia no grupo IV; e todos os acessos de $C$. argyrosperma no grupo V. O coeficiente de correlação cofenética do dendrograma $(r=0,92)$ revelou elevado ajuste entre a representação gráfica da similaridade genética e a matriz de similaridade original, o que permite a realização de inferências por meio da avaliação visual da Figura 2.

No grupo I, ficou apenas o acesso C299 (C. pepo). No grupo II ficaram dois acessos de Cucurbita pepo, C199 e C224, com um agrupamento coincidente de $73 \%$. No terceiro grupo ficaram os acessos C148, C260, C276, C222, C290, C377, e C381 todos da espécie C. pepo, sendo que estes acessos apresentaram $70 \%$ de agrupamento coincidente. A separação de diferentes acessos de $C$. реро em grupos distintos reforça o que tem sido observado em estudos de caracterização morfológica dessa espécie, que relatam a grande variabilidade genética existente (Paris, 2001; Heiden et al., 2007). O quarto grupo foi formado pelos acessos C151, C310, C312, C375 e C453, de C. ficifolia. Neste grupo os acessos apresentaram agrupamentos coincidentes de $100 \%$ mostrando que esses acessos são altamente similares diante da análise, o que era esperado, pois, representam uma espécie com pouca variabilidade genética (Heiden et al., 2007; Ferreira, 2008). O quinto grupo foi formado pelos acessos de C. argyrosperma, C16, C334, C289, C106, C103, C258, C379, C395 e C401. Neste grupo os acessos apresentaram agrupamentos coincidentes de 100\%, mostrando que são altamente similares diante da análise. Os acessos deste grupo expressam elevada semelhança fenotípica, e os resultados aqui obtidos também reforçam os relatos de baixa variabilidade genética para características morfológicas.

Os resultados obtidos confirmaram o sucesso da transferibilidade de locos SSR de C. pepo para C. argyrosperma e C. ficifolia; portanto, é possível utilizar estes primers de microssatélites na caracterização molecular dessas duas espécies. Considerando que o processo para o isolamento e desenvolvimento de primers específicos para análise de microssatélites é bastante demorado e apresenta custo elevado, os resultados obtidos nesse trabalho permitem tornar mais eficiente o processo de caracterização molecular dos recursos genéticos dessas espécies.

As análises realizadas indicam que as variedades locais de C. argyrosperma e $C$. ficifolia cultivadas no Rio Grande do Sul apresentam pouca variabilidade genética, enquanto que $C$. pepo evidencia grande variabilidade genética.

\section{AGRADECIMENTOS}

A CAPES, pela bolsa de mestrado concedida ao primeiro autor.

\section{REFERÊNCIAS}

ADONINA IG; SALINA EA; PESTSOVA EG; RÖDER MS. 2005. Transferability of wheat microsatellites to diploid Aegilops species and determination of chromosomal localizations of microsatellites in the $\mathrm{S}$ genome. Genome 48: 959-970.

BUSSAD WO; MIAZAKI ES; ANDRADE DF.
1990. Introdução à análise de agrupamentos. São Paulo: Associação Brasileira de Estatística, 105p.

CHEN SY; LIN YT; LIN CW; CHEN WY; YANG $\mathrm{CH}$; KU HM. 2010. Transferability of rice SSR markers to bamboo. Euphytica 175: 23-33.

DANIN-POLEG Y; REIS N; TZURI G; KATZIR N. 2001. Development and characterization of microsatellite markers in Cucumis. Theoretical and Applied Genetics 102: 61-72.

DICE LR. 1945. Measures of the amount of ecologic association because between species. Ecological Society of America 26: 297-302.

FERREIRA MAJF. 2008. Abóboras e morangas: das Américas para o mundo. In: BARBIERI RL; STUMPF ERT. (eds). Origem e evolução de plantas cultivadas. Brasília: Embrapa Informação Tecnológica, 59-88.

FERREIRA M; GRATTAPAGLIA D. 1998. Introdução ao uso de marcadores moleculares em análise genética. Brasília: EMBRAPA CENARGEN, 220p.

GONG L; STIFT G; KOFLER R; PACHNER M; LELLEY T. 2008. Microsatellites for the genus Cucurbita and an SSR-based genetic linkage map of Cucurbita pepo L. Theoretical and Applied Genetics 117: 37-48.

GONZÁLEZ-MARTÍNEZ SC; ROBLEDOARNUNCIO JJ; COLLADA C; DIAZ A; WILLIAMS CG; ALÍA R; CERVERA MT. 2004. Cross-amplification and sequence variation of microsatellite loci in Eurasian hard pines. Theoretical and Applied Genetics 109: 103-111.

HEIDEN G; BARBIERI RL; NEITZKE RS. 2007. Chave para identificação das espécies de abóboras (Cucurbita, Cucurbitaceae) cultivadas no Brasil. Pelotas: Embrapa Clima Temperado. 31p.

HERNANDEZ P; DORADO G; LAURIE DA; MARTINA; SNAPE JW. 2001. Microsatellites and RFLP probes from maize are efficient sources of molecular markers for the biomass energy crop Miscanthus. Theoretical and Applied Genetics 102: 616-622.

INAN N; YILDIZ M; SENSOY S; KAFKAS S; ABAK K. 2012. Efficacy of ISSR and SRAP techniques for molecular characterization of some Cucurbita genotypes including naked (hull-less) seed pumpkin. The Journal of Animal \& Plant Sciences 22: 126-136.

LEITE TL; FERREIRA MA; TARCHETTI BD; FERREIRA MAJF; AMARALZPS; BUSO GSC. 2007. Análise de transferibilidade de primers microssatélites de Cucumis melo para Cucurbita moschata e Luffa cylindrica. Brasília: Embrapa Recursos Genéticos e Biotecnologia, 10p.

LORIEUXM; NDJIONDJOPMN; GHESQUIÈRE A. 2000. A first interespecific Oryza sativa and Oryza glaberrima microsatellite-based genetical linkage map. Theoretical and Applied Genetics 100: 593-601.

OLIVEIRA MSP; SANTOS JB; AMORIM EP; FERREIRA DF. 2010. Variabilidade genética entre acessos de açaizeiro utilizando marcadores microssatélites. Ciência $e$ Agrotecnologia 34: 1253-1260.

PALOP M; PALACIOS C; GONZALEZCANDELAS F. 2000. Development 
and across-species transferability of microsatellite markers in the genus Limonium (Plumbaginaceae). Conservation Genetics 1: 177-179.

PARIS HS. 2001. History of the cultivar-groups of Cucurbita pepo. Horticultural Reviews 25: 71-170.

PRIORI D; BARBIERI RL; NEITZKE RS; VASCONCELOS CS; OLIVEIRA CS; MISTURA CC; COSTA FA. 2010. Acervo do Banco Ativo de Germoplasma de Cucurbitáceas da Embrapa Clima Temperado - 2002 a 2010. Pelotas: Embrapa Clima Temperado, $37 \mathrm{p}$.

RALLO P; TENZER I; GESSLER C; BALDONI L; DORADO G; MARTIN A. 2003. Transferability of olive microsatellite loci across the genus Olea. Theoretical and Applied Genetics 107: 940-946.

RAMOS SRR; QUEIROZ MA. 2005. Recursos genéticos de abóbora no Nordeste brasileiro. In: LIMA CLM. Recursos genéticos de hortaliças: riquezas naturais. São Luís: Instituto Interamericano de Cooperação para a Agricultura, 99-116.

RITSCHEL PS; LINS TC; TRISTAN RL; BUSO GS; BUSO JA; FERREIRA ME. 2004. Development of microsatellite markers from an enriched genomic library for genetic analysis of melon (Cucumis melo L.). BMC Plant Biology 18: 4-9.

ROHLF FJ. 2000. NTSYS- $p c$ : numerical taxonomy and multivariate analysis system, version 2.1. New York: Exeter Software, 98p.

SANTOS KL; WELTER LJ; DANTAS ACM; GUERRAM.; DUCROQUET JPHJ; NODARI RO. 2007. Transference of microsatellite markers from Eucalyptus spp. to Accasello wiana and the successful use of this technique in genetic characterization. Genetics and Molecular Biology 30: 73-79.

SCHUSTER I; VIEIRA ESN; PADILHA L. 2006. Marcadores moleculares no pósmelhoramento. In: BORÉM A; CAIXETA ET. Marcadores moleculares. Viçosa: Universidade Federal de Viçosa, 205-230.

SHARMA PC; WINTER P; BUNGER T; HUTTEL B; WEINGAND F; WEISING K; KAHL G. 1995. Abundance and polymorphism of di, tri and tetranucleotide tandem repeats in chickpea (Cicerari etinum L.). Theoretical and Applied Genetics 90: 90-96.

SOKAL RR; ROHLF FJ. 1962. The comparison of dendrograms by objective methods. Taxon 11: $33-40$.

VALLS JFM. 2001. Caracterização de recursos genéticos vegetais. In: NASS LL. Recursos genéticos vegetais. Brasília: Embrapa Recursos Genéticos e Biotecnologia, 281-305.

WEIR BS. 1996. Genetic data analysis II Methods for Discrete Population Genetic Data. Sinauer Associates $377 \mathrm{p}$.

WUENSCH A; HORMAZA JI. 2002. Molecular characterization of sweet cherry (Prunus avium L.) genotypes using peach [(Prunus persica L.) Batsch] SSR sequences. Heredity 89: 56-63.

YAMAMOTO T; KIMURA T; SAWAMURA Y; KOTOBUKI K; BAN Y; HAYASHI T; MATSUATA N. 2001. SSRs isolated from apple can identify polymorphism and genetic diversity in pear. Theoretical and Applied Genetics 102: 865-870.

YAP IV; NELSON RJ. 1996. Winboot: a program for performing bootstrap analysis of binary data to determine the confidence limits of UPGMA-based dendrograms. Manila: IRRI, 22p.

ZUCCHI MI; BRONDANI RPV; PINHEIRO JB; CHAVES LJ; COELHO ASG; VENCOVSKY R. 2003. Genetic structure and gene flow in Eugenia dysenterica DC in the Brazilian Cerrado utilizing SSR markers. Genetics and Molecular Biology 26: 449-457. 